\title{
Impact of anthropogenic and natural environmental changes on Echinococcus transmission in Ningxia Hui Autonomous Region, the People's Republic of China
}

\author{
Yu Rong Yang ${ }^{1,2,3^{*}}$, Archie C A Clements ${ }^{4}$, Darren J Gray ${ }^{1,4}$, Jo-An M Atkinson ${ }^{4}$, Gail M Williams ${ }^{4}$,
}

Tamsin S Barnes ${ }^{5}$ and Donald P McManus ${ }^{1}$

\begin{abstract}
Echinococcus transmission is known to be affected by various environmental factors, which may be modified by human influence or natural events including global warming. Considerable population growth in the last fifty years in Ningxia Hui Autonomous Region (NHAR), the People's Republic of China (PRC), has led to dramatic increases in deforestation and modified agricultural practices. In turn, this has resulted in many changes in the habitats for the definitive and intermediate hosts of both Echinococcus granulosus and E. multilocularis, which have increased the risks for transmission of both parasites, affecting echinococcosis prevalence and human disease. Ecological environmental changes due to anthropogenic activities and natural events drive Echinococcus transmission and NHAR provides a notable example illustrating how human activity can impact on a parasitic infection of major public health significance. It is very important to continually monitor these environmental (including climatic) factors that drive the distribution of Echinococcus spp. and their impact on transmission to humans because such information is necessary to formulate reliable future public health policy for echinococcosis control programs and to prevent disease spread.
\end{abstract}

Keywords: Ningxia Hui Autonomous Region of the Peoples Republic of China, Echinococcus transmission, Environmental changes, Intermediate host, Definitive host

\section{Review}

Introduction

Globally, the zoonotic disease echinococcosis (hydatidosis) is one of the most important parasitic helminth diseases, with over three million people infected worldwide [1]. The two major species infecting man are Echinococcus multilocularis, causing alveolar echinococcosis (AE), and Echinococcus granulosus, the cause of cystic echinococcosis $(\mathrm{CE})$. It is estimated that there are 0.38 million people with echinococcosis in China $[2,3]$ and the

\footnotetext{
* Correspondence: Yurong.Yang@qimr.edu.au

${ }^{1}$ Molecular Parasitology Laboratory, Queensland Institute of Medical

Research, Brisbane, Queensland, Australia

${ }^{2}$ Ningxia Medical University, Yinchuan, Ningxia Hui Autonomous Region, P. R. of China

Full list of author information is available at the end of the article
}

disease burden in Disability-Adjusted Life-Years (DALYs) lost is greater there than any other country [4]. Of the 33 provinces/autonomous regions, 20 are considered to be endemic for E. granulosus and five for E. multilocularis [2,5]. Ningxia Hui Autonomous Region (NHAR) is hyper-endemic for both $\mathrm{AE}$ and $\mathrm{CE}$ in humans and animals, with some of the highest infection rates recorded anywhere [6]. Although there are many risk factors impacting upon the transmission dynamics of the Echinococcus species, the link between climate variables and disease risk from these parasites is increasingly being recognized [7]. Concern has been raised about the potential impact of climate change on the burden of echinococcosis [7-11], due to its direct influence on the Echinococcus free-living egg stage and its indirect influence on host species abundance and distribution through modification of food source availability and

\section{Biomed Central}


migration patterns. Additionally, the maintenance and persistence of the parasitic life-cycles requires stable predator-prey relationships that can be disrupted by environmental change $[7,9,12]$.

Environmental factors impact on the density of intermediate hosts and affect egg survival, which is governed by ground temperature, moisture and precipitation. In the case of the small mammalian hosts of E. multilocularis, density is determined by the presence of certain vegetation types that provide suitable habitats, whereas for E. granulosus transmission, it is influenced by grassland availability for livestock [13]. Human echinococcosis is associated with poverty and poor hygiene practices, particularly in livestock-raising communities where the natural environment is suitable to maintain the life-cycle. Lack of adequate water and sanitation systems also contribute considerably to transmission as a result of contamination of the water supply with faeces from parasitised hosts [14]. NHAR is one of the poorest provinces in China [15], where a large number of people, particularly among the Hui Muslims, an ethnic minority comprising one third of the population [16], raise livestock. Previously published data of clinical records and the results of mass screening have shown that $\mathrm{CE}$ occurs throughout NHAR whereas AE occurs predominantly in a confluence area of three counties (Xiji, Guyuan and Haiyuan) [6]. Here we review the environmental (including climatic) factors that drive the distribution of

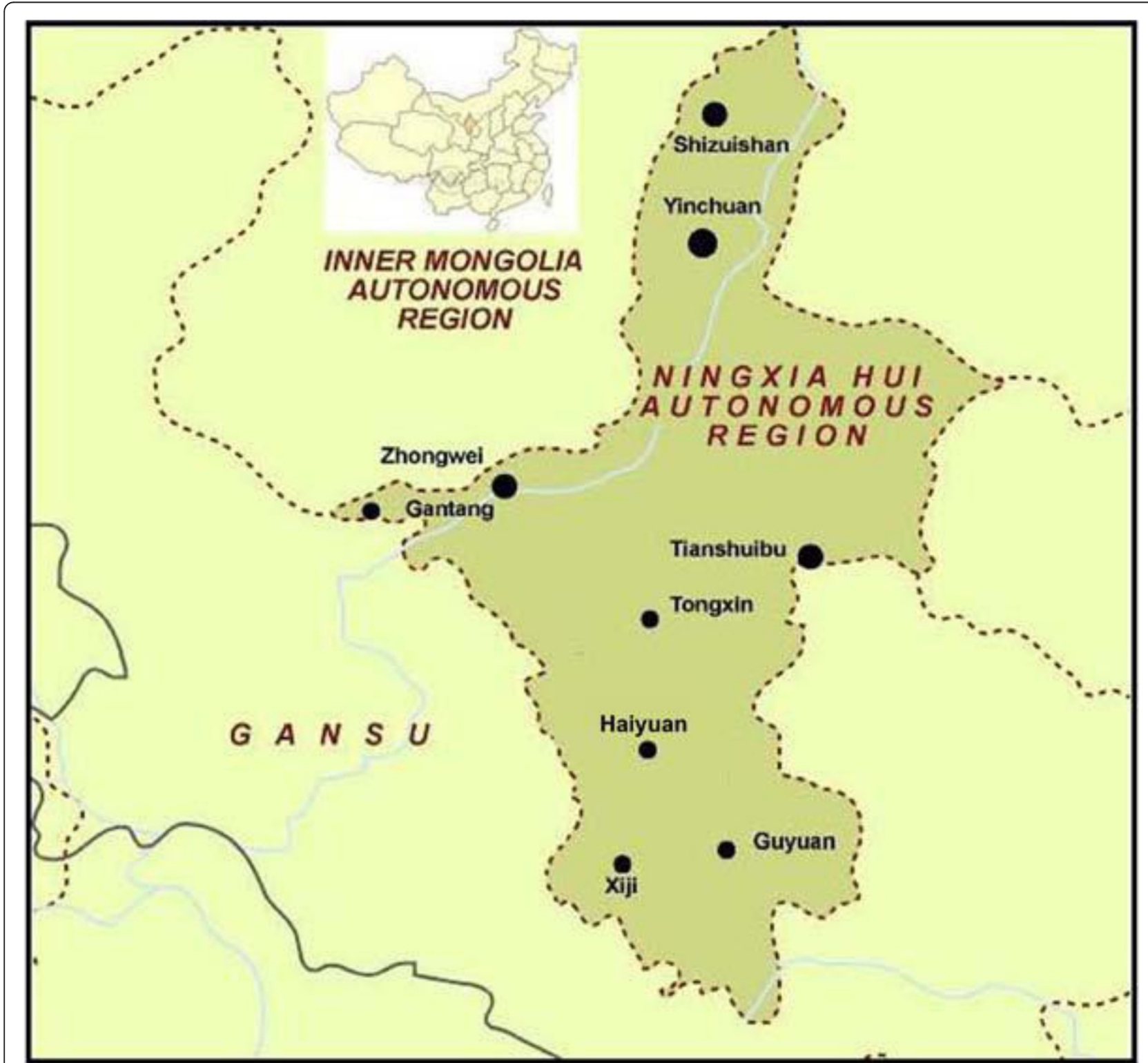

Figure 1 Location of Ningxia Hui Autonomous Region (NHAR) within China and its major cities and towns. 
Echinococcus spp. and their impact on human transmission in NHAR.

\section{Environmental change over time}

NHAR (Figure 1), located in Northwest China [17], has a continental climate with average temperatures that generally peak at $17-24^{\circ} \mathrm{C}$ in July and drop to $-7--10^{\circ} \mathrm{C}$ in January. Temperatures can, however, reach extremes of $39^{\circ} \mathrm{C}$ in summer and $-30^{\circ} \mathrm{C}$ in winter. The diurnal temperature variation can exceed $17^{\circ} \mathrm{C}$, especially in spring. Average annual rainfall varies from 190 to 700 $\mathrm{mm}$, with more rain falling in the south of the region $[18,19]$. The natural geographic features divide NHAR into two main regions, northern and southern NHAR [20]. Although NHAR is sparsely settled, the vast plain of the Yellow River in the north has been irrigated for centuries and, over the years, an extensive system of canals has been built. Desert and grazing land make up most of the area except the northern fertile plain, which is ideal for growing crops and breeding livestock. In contrast to the northern parts, southern NHAR is mountainous and the people mainly raise livestock with limited farmland. No irrigation systems are present in the south and animal husbandry and agriculture are critically dependent on the environmental and climatic conditions prevailing throughout the year.

Similar to the rest of China the population of NHAR has increased rapidly over the past 50 years (Figure 2), especially among the Hui community, resident in the south. This is due to the Chinese Government's family planning policy, whereby a Chinese Han couple is permitted only one child whereas for ethnic minorities, two to three children are allowed. The marked population growth generally in NHAR has resulted in a substantial increase in the requirement for agricultural land, which has, in turn, resulted in extensive deforestation $[16,17,21]$.

From the late 1970s to the early 2000s, NHAR lost large areas of original natural grassland due to urbanisation and the formation of cropland and woodland [8]. This was particularly the case in southern NHAR where land use changes (Figure 2) have resulted in the majority of livestock grazing land having been converted into terraced fields for production of wheat, potatoes, beans and alfalfa. This type of farmland has been extended to lower altitudes during the past five decades [8]. There is little

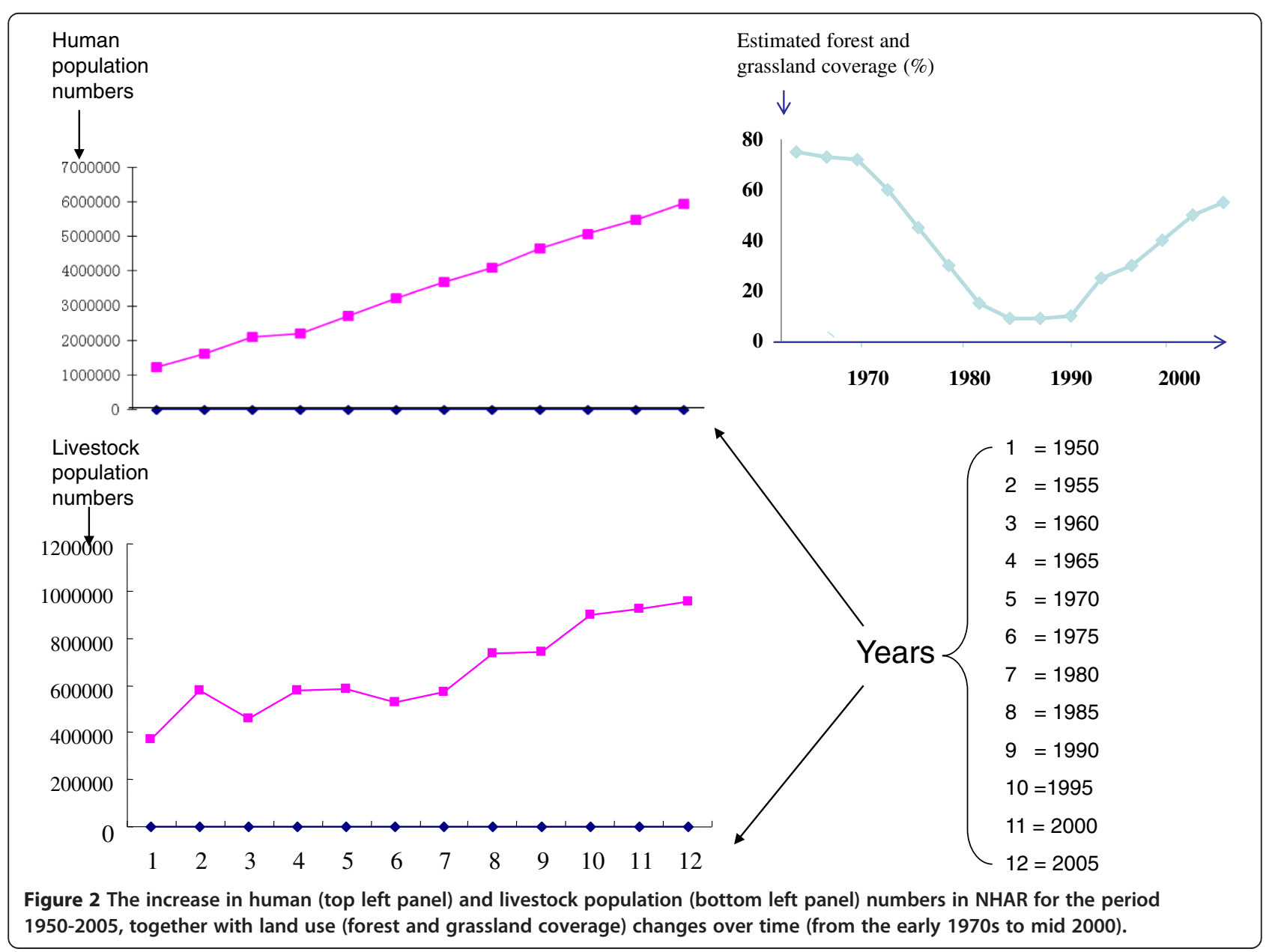




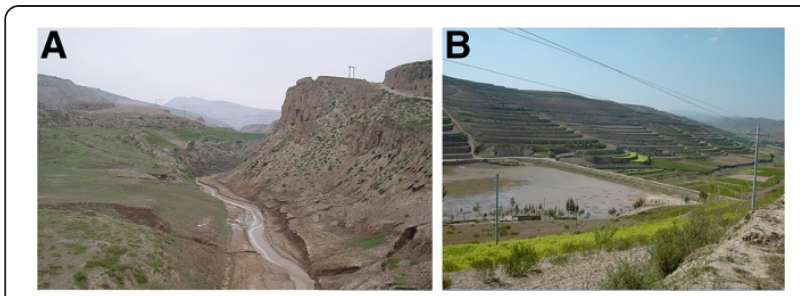

Figure 3 Photographs taken in southern NHAR in 2002-2003 showing erosion and sparse vegetation following deforestation and over-grazing by livestock (A); and creation of terraced agricultural farmland (B).

or no natural vegetation left in the southern parts of NHAR following these periods of deforestation and a move towards more intensive agricultural production (Figure 3) [13]. At higher elevations of the Liupan Mountain range, which extends southward from NHAR across the eastern panhandle of Gansu province and into western Shaanxi province, pasture land was predominant several decades ago [8]. Currently, much of the remaining forest on southern Liupan Mountain (2100$2800 \mathrm{~m}$ ) consists of secondary forest, although some patches of pristine forest can still be found [9]. Local government records indicate that, during the late 1970s, the valleys and lower slopes of southern NHAR were generally used for agricultural cropland while the upper slopes and hill tops were reserved for grazing [8,22]. This natural landscape has been modified into an artificial landscape comprising farmland and urban areas (Figure 2). Wildlife biodiversity has been affected by increasing soil erosion, changing local climatic conditions, such as more frequent droughts, floods and seasonal sand storms, and an increase in pest species. This is most pronounced in the mountainous areas of southern NHAR, where there used to be substantial wildlife habitats, and an abundance of foxes, wolves, dogs and wild large and small herbivorous mammals.

The Chinese government is currently attempting to reforest eroded landscapes (Figure 4) and therefore sheep grazing has been reduced over the majority of NHAR, particularly in the south with a total ban on hill tops and upper slopes where trees are due to be planted [9]. As

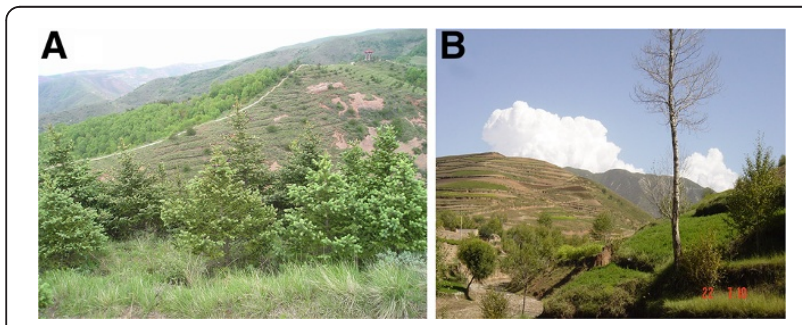

Figure 4 Photographs taken in southern NHAR in 2009-2011 showing reforestation of both grazing land $(A)$ and previously terraced farmland (B). an unintended consequence, the regenerated landscape may become favourable again to populations of small mammal intermediate hosts of Echinococcus spp. [13]. Rehabilitation of degraded areas has been shown to cause increased population densities of intermediate hosts (especially) and definitive hosts (dogs and foxes) for Echinococcus spp. [9]. Additionally, legislation banning indiscriminate use of rodenticides in NHAR from 2002 has further added to increases in the rodent and dog populations $[8,13]$.

\section{Echinococcus spp. life-cycle in animals and transmission to humans}

Definitive hosts of E. granulosus in NHAR are dogs and other canids while intermediate hosts include sheep, goats, swine, cattle, horses, camels and, according to our recent research findings, rodents [13] and other small mammals, such as lagomorphs [23]. E. multilocularis has a similar life cycle to E. granulosus with the main definitive hosts being foxes and dogs, and the intermediate hosts are small mammals especially rodents. Roaming domestic dogs can provide a transmission link between the sylvatic cycle and humans, thereby increasing the risk of human infection. It is known that dogs are generally highly susceptible to infection with E. multilocularis [24]. Free-roaming/scavenging behavior leads to infection, especially in under-developed southern NHAR where dogs are poorly fed and there is a large population of small mammals in close proximity to households. Humans become accidentally infected by ingesting Echinococcus eggs from any of three sources: an eggcontaminated natural environment; ingestion of contaminated foodstuffs or water; or through direct contact (e.g. playing) with infected domestic dogs. After ingestion, the eggs release oncospheres in the intestine leading to the development of cysts in various organs [25], particularly the liver [6]. It can take up to 10-15 years for the symptoms of infection to manifest and be diagnosed [2].

\section{Intermediate hosts}

Rodents/small mammals Historically, the first report from southern NHAR of the ground squirrel, Spermophilus dauricus and S. alashanicus infected with E. multilocularis was in 1985 [26,27]. Both Spermophilus spp. and Myospalax fontanieri were found to be infected with fertile AE cysts containing protoscoleces [28]. Other suitable intermediate hosts such as Cricetulus spp. and Meriones unguiculatus were recorded in scrub and grassland in the Liupan Mountains [29], though without parasitological examination. During the 1980s, prevalence of $\mathrm{AE}$ was $0.6 \%$ in Citellus spp, $0.2 \%$ in Citellus dauricus, and $0.3 \%$ in Myospalax fontanierii [26]. 
The relationship between landscape and small mammal population dynamics in regulating E. multilocularis transmission has been studied extensively. A strong environmental predictor of small mammal habitat suitability is the ratio of optimal to marginal patch area (ROMPA) [12]. Landscape changes can have a major effect on small mammal communities and may play a role modifying cestode transmission patterns involving small mammals. For example, deforestation may increase the area of habitats favourable for Spermophilus dauricus/ alashanicu, also referred to as S. dauricua or Myospalax fontanieri [13]. This large rodent is one of the commonest rodent species in the southern NHAR area (accounting for around $80-85 \%$ of all rodent species) [18], largely occurring in fields, fallow areas and in areas with early re-forestation $[8,13]$. It was also recently found to be susceptible to natural, patent infection with the larvae of E. granulosus [13]. Despite providing no definitive proof of a cycle involving ground squirrels and dogs/foxes, this finding highlights the possibility for high transmission intensity due to heavy environmental contamination with E. granulosus eggs $[8,13,30]$ in this region of NHAR. The study also indicated that rodents can be shared intermediate hosts for E. multilocularis and E. granulosus [13], and that they may serve as valuable indicators for assessing the occurrence and the level of environmental contamination with eggs of these parasites and the infection pressure resulting.

Livestock Families in the southern rural areas of NHAR, usually raise sheep and cattle, and keep dogs to help manage their livestock. When necessary, livestock are slaughtered by the owners, close to their dwellings and often near a river bank, to facilitate the washing of carcasses. Owners report feeding raw viscera (sometimes known to have hydatid cysts) to their dogs or they discard the viscera, especially if they contain cysts. It is likely that free-roaming dogs become infected with E. granulosus after feeding on discarded sheep offal containing larval E. granulosus. An investigation in the mid1980s found the prevalence of CE in sheep in Xiji, Haiyuan and Guyuan (XHG) counties to be $79 \%$ and $40 \%$ in Tongxin County [18]. In the same study, the prevalence in goats in Tongxin was 21\% [18]. Up until the late 1990s, livestock records from local abattoirs showed a high prevalence of CE in sheep (52\%), cattle (81\%), pigs $(24 \%)$ camels $(19 \%)$ and goats $(3 \%)$, in the hyper-endemic counties of NHAR [31].

Re-forestation of eroded landscapes started in NHAR from the beginning of the 1990s, limiting the land available for sheep grazing. Sheep and other livestock are raised generally in enclosed yards, and the numbers of livestock kept by families have been reduced [8]. CE is still found regularly in sheep and other livestock in abattoirs although recent reports suggest that the occurrence of infected animals at slaughter is lower than 20 years ago [32]. Infection in sheep usually occurs on farms where domestic dog management is poor and/or where there is a problem with large populations of roaming dogs. Infected dogs will contaminate the pasture with eggs of E. granulosus, which sheep ingest while grazing. According to earlier reports, E. multilocularis can be found under natural conditions in various mammalian hosts (e.g. horses, domestic and wild pigs) but they do not play a role in the transmission cycle [33]. As far as we are aware, there have been no reports of larval E. multilocularis infection in Chinese livestock. Suspected E. multilocularis infection in Tibetan yaks was found to be misdiagnosed [34].

\section{Definitive hosts}

Dogs and foxes In the mid-1980s, Li and colleagues were the first to report E. multilocularis infection in foxes in NHAR, finding 3/20 (15\%) trapped red foxes from Xiji and Guyuan Counties to be infected [18,27]. The infection intensity varied from 1,840-4,050 tapeworms. This investigation also found 4/385 (1\%) domestic dogs in Xiji County infected with E. granulosus by necropsy. Veterinary records of necropsies from Tongxin County in 1991-92 indicated an infection prevalence of over $55 \%$ in dogs [31]. However, in the two decades since then, there has been a lack of veterinary surveillance data, possibly for two reasons: 1) the government veterinary service in NHAR has received poor financial support from the mid-1990s, since restructuring of the economic system [17], resulting in a lack of trained staff; and 2) the dog populations dramatically declined due to the introduction in the early 1990s of rodenticides (used in poisoned baits) to control the large rodent population present, resulting in inadvertent poisoning of a large number of dogs. As we described in a previous report [9], intensive deforestation and increased ploughing of fields resulted in an increase in the local rodent population, and a reduction in the numbers of predators (particularly foxes) due to the loss of habitat. When we undertook community surveys at the beginning of the 2000s, dogs were completely absent in some villages in southern rural NHAR, or only rarely in others [21], where dogs used to be numerous [18,22]. In contrast, in urban areas of southern NHAR, the population of dogs, which are generally well-fed, remained constant. From 2002, the dog population in rural villages grew dramatically because of the local government regulations prohibiting the use of anticoagulant drugs (used as rodenticides) and their sale in markets [8]. According to veterinary reports, the dog population (including stray and owned dogs) is currently similar in number to the 
human population in some counties of southern NHAR [32]. This change may lead to increased risk of human $\mathrm{AE}$ or $\mathrm{CE}$ if it is coupled with increased densities of small mammal species susceptible to the Echinococcus spp., due to the environmental changes occurring, and a failure to prevent home slaughter of livestock animals and poor management of raw viscera.

\section{Social and behavioural factors influencing transmission}

Rural villagers in NHAR engage daily in the collection of herbs and wild vegetables and hunting of wild animals, especially large mammals. Sheep farming is also a major economic activity for these rural communities, especially those dominated by the Hui ethnic group (Figure 2). Because there has been almost a complete lack of piped water in past decades, these people have relied mainly on natural sources such as seasonal rivulets, rain collection and temporary wells dug in dry-river beds for their water supply. Livestock and domestic dogs, together with wild animals, are allowed free access to these water supplies, leading to contamination with animal faeces, thereby increasing the risk of the transmission of Echinococcus spp.[13]. Indeed, our recent human surveys in NHAR revealed considerable numbers of patients with $\mathrm{CE}$ and $\mathrm{AE}$ [21], reflecting a high level of Echinococcus transmission over previous decades since the incubation periods of human $\mathrm{CE}$ and $\mathrm{AE}$ are generally very long (about 10-15 years).

Farming households in rural NHAR typically have a well (often uncovered), in addition to stables and pens for livestock, dog kennels and latrines within the vicinity of the dweling. On a daily basis, human faeces ('nightsoil') and livestock and dog faeces are mixed with soil to create compost for use as fertiliser. The compost is generally stored in a corner of the yard, a practice that may not only increase Echinococcus egg survival time if any are present in dog faeces, but which also increases the chance of contaminating the local water supply (e.g. nearby wells) with ova when heavy rainfall occurs. Additionally, water for consumption is usually not boiled by these rural communities [21].

\section{Changes in human echinococcosis prevalence/incidence over time}

Up until the late 1980s, 304 human AE cases had been diagnosed from the hyperendemic southern counties of NHAR [19]. A mass-screening survey conducted in communities in Xiji County in 1989 [35] indicated that in two townships (Xinying and Baiya), $8.2 \%$ of subjects had echinococcosis, including 5.9\% with $\mathrm{AE}$ and 2.3\% with CE. Diagnosis was by ultrasound and serology and subjects were aged 19-72 years [35]. Another community survey using ultrasound in Yumu village in 1996 showed a human AE and CE prevalence of 4.6\% [19]. A total of 113 clinical AE cases were diagnosed in Guyuan hospital between 1965 and 1991 [36]. Two reports had described family clusters of cases [22,37]; these families hunted ground squirrels (Spermophilus spp. for meat and gave the raw viscera to their dogs [22]. Previous incidence values recorded for human echinococcosis in other parts of China [37] and in NHAR [20] were under-estimates, because the hospital records would have excluded individuals who were asymptomatic, or who had not sought clinical advice due to their poor economic status. Therefore, active surveys, undertaken (2001-2003) in communities in Xiji, Guyuan and Longde counties, showed a heterogeneous prevalence between communities, ranging from $0-8 \%$ (mean $2 \%$ ) for $\mathrm{AE}$ and $0-7.4 \%$ (mean $1.6 \%$ ) for $\mathrm{CE}$, although the overall prevalence was lower $(3.6 \%)$ than in previous reports [21]. The variable prevalence of human $\mathrm{AE}$ and $\mathrm{CE}$ among communities may be associated with different microenvironmental features of the localities.

The co-existence of both $\mathrm{AE}$ and $\mathrm{CE}$ in most communities within southern NHAR indicates that the environment was conducive to the transmission of both forms of the disease. Although human CE cases have been found throughout the whole of NHAR, the absence of $\mathrm{AE}$ in the north may be attributed to the hot and dry climate and other risk factors providing unsuitable conditions for E. multilocularis egg survival [38]. Clinical records (1992-2002) for the whole of NHAR showed an age range of cases of $1-80$ years for $C E$, but $21-70$ years for $\mathrm{AE}$ [6]. By contrast, community surveys [21], only conducted in southern parts (Xiji, Guyuan and Longde counties) of NHAR in 2002-2003, found an age range of 19-79 for both AE and CE. This indicates that there were very different spatial patterns of transmission in the intervening period. The age distribution of patients (many older-aged patients and few younger-aged patients) provides indirect evidence that $\mathrm{AE}$ and $\mathrm{CE}$ transmission had been very high some decades ago but had been reduced (even stopped) by the collapse in definitive host (dogs/fox) populations in southern NHAR due to anthropogenic environmental change and the changes in policy described earlier $[8,9]$. The relative youth of some CE patients (identified using hospital records) indicated $\mathrm{CE}$ transmission was still very active in other areas of NHAR compared with the south [6].

While clinical echinococcosis was found to be very rare in young people in a recent investigation [39], seroprevalence amongst this group showed an increased trend in many southern NHAR communities [21,30]. Exposure to Echinococcus can be diagnosed after only a few months by identifying specific antibodies in human serum [40]. The increase in sero-prevalence among younger subjects is of concern because it suggests that the incidence of clinical cases is likely to rebound in 
NHAR, with an increase in the burden of echinococcosis in coming decades.

\section{Changes in the transmission patterns of echinococcosis over time}

The micro-climate is important for the survival rates of Echinococcus eggs once they have been shed into the environment $[9,41]$. The higher concentration of infectious definitive host faeces can lead to parasite over-dispersion , which, for example, can be caused by eggs spreading widely, due to rain or washing, or the use of faeces as fertiliser. Additionally, the burying of faeces (e.g. by cattle compacting and turning over soil, by the deposition of eggs into muddy soil near water courses or by humans mixing manure and soil to form compost) may increase parasite egg survival rates [7], thus increasing the likelihood of their ingestion by intermediate hosts and humans. Furthermore, the behaviour of local subgroups of foxes or stray dogs around a village may be more important than the common behaviour of the total canine host population for human infection [10].

The landscape composition and structure of microareas is also important for the maintenance of small mammal and fox populations, thereby ensuring the completion of a wildlife cycle for E. multilocularis. Landscapes with pasture and grassland are also important for the provision of grazing for sheep and other livestock, which are necessary to maintain a domestic cycle for E. granulosus. The impact of these landscape and microenvironmental factors was emphasised by a recent series of studies which found evidence of hot-spots of transmission and geographical clusters of human $\mathrm{AE}$ and $\mathrm{CE}$ cases $[10,12,16]$ that have changed over time. Clear evidence of this is provided by the heterogeneous distribution we described earlier of human $\mathrm{AE}$ and $\mathrm{CE}$ cases in various communities of southern NHAR [21]. Furthermore, a previous community survey that we undertook in a hyper-endemic area in NHAR (Xiji County) using filter paper blood-enzyme-linked immunosorbent assay (ELISA) for human antibody detection against E. multilocularis protosocolex antigen (anti-EmP) - which measures E. multilocularis egg exposure - revealed that sero-prevalence significantly increased in children in some village communities (Huoshizhai and Nanwan), whereas in others (e.g. Haoziwan), the sero-prevalence, detected by ELISA against E. granulosus hydatid cyst fluid lipoprotein antigen (anti-EgB) - which indicates E. granulosus egg exposure - had decreased [30] (Table 1). This combined evidence illustrates the fact that transmission of the Echinococcus spp. has changed spatiotemporally, together with simultaneous environmental and climatic changes in rural southern NHAR [30]. Similar findings have been reported from other echinococcosis-endemic areas worldwide [11].
Table 1 The presence (+) or absence (-) of sero-positive teenagers and ultrasound-detected adult cases of cystic and alveolar echinococcosis in various village communities in hyper-endemic Xiji County, People's Republic of China from 2001-3 [21,30]

\begin{tabular}{lcccc}
\hline & \multicolumn{2}{c}{ Ultrasound detected cases } & \multicolumn{2}{c}{ Sero-positive subjects } \\
\hline Age range & \multicolumn{2}{c}{$20-79$ yrs old } & \multicolumn{2}{c}{ 6-18 yrs old } \\
\hline Disease $^{\text {a }}$ & AE & CE & Anti-Em & Anti-Eg \\
\hline Huoshizhai $^{\text {d }}$ & + & + & + & - \\
\hline Nanwan & + & + & + & - \\
\hline Haoziwan & + & + & - & + \\
\hline Zhangcunpu & + & + & + & + \\
\hline Bai'ai & + & + & + & + \\
\hline Baicheng & - & + & + & + \\
\hline
\end{tabular}

${ }^{\mathrm{a}} \mathrm{AE}$, alveolar echinococcosis; $\mathrm{CE}$, cystic echinococcosis.

${ }^{\mathrm{b}}$ Anti-Em, exposure to E. multilocularis eggs measured by anti-EmP ELISA. ${ }^{c} A n t i-E g$, exposure to E. granulosus eggs measured by anti-EgB ELISA. ${ }^{\mathrm{d}}$ Name of village community.

\section{Potential spread of Echinococcus}

The Chinese government has changed its policy to reforestation of eroded landscapes in NHAR. As a result, landscapes there may become favourable again for Echinococcus spp. transmission when the intermediate stages of forest succession become widespread and the improved environmental conditions provide suitable wildlife habitats for rodents and foxes and increased grazing resources for livestock. If these circumstances are coupled with immigration of Echinococcus-infected definitive hosts, this will allow the parasites to disperse within these new areas. Currently, there is an increasing market throughout China for guard dogs [9]. If there is no regulatory system and limited inspections to monitor diseases in dogs, this trade could contribute to the dispersal and transmission of Echinococcus spp. within China. Dogs will present a major risk for spreading these parasites to non-endemic areas not only in NHAR but elsewhere in China, such as the Tibetan plateau, where the situation for transmission may be comparable.

\section{The implementation of control measures for echinococcosis in NHAR and the challenge}

The transmission and the risk of Echinococcus infection can increase as the result of anthropogenic and natural environmental changes in NHAR, but control, if implemented effectively, can limit the effect. The national echinococcosis control program (NECP) for China, which was supported and launched by the Chinese Government in 8 provinces/autonomous regions from 2005 [3], has been in place in NHAR since 2006. The main activities of the NECP, which include canine purgation and praziquantel treatment of registered dogs, culling of unwanted and stray dogs, health education, and improved slaughter house management and inspection 
of livestock carcasses, have already impacted favourably on echinococcosis control in NHAR [42]. A major challenge to control of echinococcosis in NHAR is the very large numbers of stray dogs, not only in rural areas but also in cities [43], which increases the likelihood of continual transmission.

\section{Conclusions}

It is very important to understand the natural history of the transmission cycles of echinococcosis in NHAR in order to quantify the impact of the $20-30$ year process of deforestation, agricultural expansion and land use changes on the disease. These anthropogenic acitivities have led to dramatic natural environment changes and ecological diversities of the hosts of Echinococcus spp., consequently affecting parasite transmission between animal and human hosts. It is vital that such information, based on detailed and continually updated epidemiological data, is obtained to assist in the design of cost-effective public health programs to control echinococcosis in NHAR and other areas of China endemic for the disease.

\section{Competing interests}

The author(s) declare that they have no competing interests.

\section{Authors' contributions}

YRY and DPM conceived the idea for the review. YRY prepared the first draft of the manuscript. DPM, ACAC, DJG, J-AA, GMW and TSB provided critical comments and helped in drafting subsequent revisions. DPM finalised the manuscript. All authors read and approved the final manuscript.

\section{Acknowledgements}

We acknowledge financial support by the National Health and Medical Research Council (NHMRC) of Australia (APP1009539) and the Natural Science Foundation of China (NSFC) (30960339) for our studies on echinococcosis. DJG is an Australian Research Council Fellow (DECRA); DPM is a NHMRC Senior Principal Research Fellow; ACAC is a NHMRC Career Development Fellow.

\section{Author details \\ 'Molecular Parasitology Laboratory, Queensland Institute of Medical Research, Brisbane, Queensland, Australia. ${ }^{2}$ Ningxia Medical University, Yinchuan, Ningxia Hui Autonomous Region, P. R. of China. ${ }^{3}$ Griffith Health Institute, Griffith University, Brisbane, Queensland, Australia. ${ }^{4}$ School of Population Health, University of Queensland, Brisbane, Queensland, Australia. ${ }^{5}$ University of Queensland, Queensland Alliance for Agriculture and Food Innovation, Gatton, Queensland, Australia.}

Received: 11 May 2012 Accepted: 24 July 2012

Published: 24 July 2012

\section{References}

1. Zhang W, Ross AG, McManus DP: Mechanisms of immunity in hydatid disease: implications for vaccine development. I Immunol 2008, 181:6679-6685.

2. McManus DP, Zhang W, Li J, Bartley PB: Echinococcosis. Lancet 2003, 362:1295-1304.

3. Chai J-J: Echinococcosis control in China: Challenges and Research Needs. Chin J Parasitol Control and Parasit Dis 2009, 27:379-383.

4. Budke CM, Jiamin Q, Qian W, Torgerson PR: Economic effects of echinococcosis in a disease-endemic region of the Tibetan Plateau. AmJTrop Med Hyg 2005, 73:2-10.
5. Vuitton DA, Zhou H, Bresson-Hadni S, Wang Q, Piarroux M, Raoul F, Giraudoux P: Epidemiology of alveolar echinococcosis with particular reference to China and Europe. Parasitology 2003, 127(Suppl):S87-S107.

6. Yang YR, Cheng L, Yang SK, Pan X, Sun T, Li X, Hu S, Zhao R, Craig PS, Vuitton DA, et al: A hospital-based retrospective survey of human cystic and alveolar echinococcosis in Ningxia Hui Autonomous Region, PR China. Acta Trop 2006, 97:284-291.

7. Danson FM, Giraudoux P, Craig PS: Spatial modelling and ecology of Echinococcus multilocularis transmission in China. Parasitol Int 2006, 55 (Suppl):S227-S231.

8. Pleydell DR, Yang YR, Danson FM, Raoul F, Craig PS, McManus DP, Vuitton DA, Wang Q, Giraudoux P: Landscape composition and spatial prediction of alveolar echinococcosis in southern Ningxia. China. PLoS Negl Trop Dis 2008, 2:e287.

9. Giraudoux P, Pleydell D, Raoul F, Quere JP, Wang Q, Yang Y, Vuitton DA, Qiu J, Yang W, Craig PS: Transmission ecology of Echinococcus multilocularis: what are the ranges of parasite stability among various host communities in China? Parasitol Int 2006, 55(Suppl):S237-S246.

10. Danson FM, Graham AJ, Pleydell DR, Campos-Ponce M, Giraudoux P, Craig PS: Multi-scale spatial analysis of human alveolar echinococcosis risk in China. Parasitology 2003, 127(Suppl):S133-S141.

11. Romig T, Thoma D, Weible AK: Echinococcus multilocularis-a zoonosis of anthropogenic environments? J Helminthol 2006, 80:207-212.

12. Giraudoux P, Craig PS, Delattre P, Bao G, Bartholomot B, Harraga S, Quere JP, Raoul F, Wang Y, Shi D, et al: Interactions between landscape changes and host communities can regulate Echinococcus multilocularis transmission. Parasitology 2003, 127(Suppl):S121-S131.

13. Yang YR, Liu T, Bai X, Boufana B, Craig PS, Nakao M, Ito A, Zhang JZ, Giraudoux P, McManus DP: Natural infection of the ground squirrel (Spermophilus spp.) with Echinococcus granulosus in China. PLoS Negl Trop Dis 2009, 3:e518.

14. Craig PS, Li T, Qiu J, Zhen R, Wang Q, Giraudoux P, Ito A, Heath D, Warnock $B$, Schantz $P$, et al: Echinococcosis and Tibetan communities. Emerg Infect Dis 2008, 14:1674-1675.

15. Sun Q, Liu X, Meng Q, Tang S, Yu B, Tolhurst R: Evaluating the financial protection of patients with chronic disease by health insurance in rural China. Int J Equity Health 2009, 8:42.

16. Yang YR, Ellis M, Sun T, Li Z, Liu X, Vuitton DA, Bartholomot B, Giraudoux P, Craig PS, Boufana B, et al: Unique family clustering of human echinococcosis cases in a chinese community. Am J Trop Med Hyg 2006, 74:487-494.

17. Yang YR, Williams GM, Craig PS, McManus DP: Impact of increased economic burden due to human echinococcosis in an underdeveloped rural community of the People's Republic of China. PLoS Negl Trop Dis 2010, 4:e801.

18. Li W: Investigation of hosts of Echinococcus multilocularis in Ningxia.: Endemic Dis Bull; 1986:131-135.

19. EPSNR (Prevention station of Ningxia Hui Autonomous Region): Current status of echinococcosis in Ningxia, China. Urumqi, Xinjiang: In Proceedings of the Workshop on Echinococcosis Control Strategy in China: 1999; 1999:1-6. Institute for Endemic Disease Research and Control.

20. Yang YR, Williams GM, Craig PS, Sun T, Yang SK, Cheng L, Vuitton DA, Giraudoux P, Li X, Hu S, et al: Hospital and community surveys reveal the severe public health problem and socio-economic impact of human echinococcosis in Ningxia Hui Autonomous Region, China. Trop Med Int Health 2006, 11:880-888.

21. Yang YR, Sun T, Li Z, Zhang J, Teng J, Liu X, Liu R, Zhao R, Jones MK, Wang $Y$, et al: Community surveys and risk factor analysis of human alveolar and cystic echinococcosis in Ningxia Hui Autonomous Region, China. Bull World Health Organ 2006, 84:714-721.

22. Li M, Wang H, Yin YC, Li W: B-ultrasound diagnosis of hepatic alveolar echinococcosis in 141 cases. Gansu Med J 1990, 9:89-90.

23. Xiao N, Li TY, Qiu JM, Nakao M, Chen XW, Nakaya K, Yamasaki H, Schantz PM, Craig PS, Ito A: The Tibetan hare Lepus oiostolus: a novel intermediate host for Echinococcus multilocularis. Parasitol Res 2004, 92:352-353.

24. Tiaoying $L$, Jiamin Q, Wen $Y$, Craig PS, Xingwang C, Ning X, Ito A, Giraudoux P, Wulamu M, Schantz PM: Echinococcosis in Tibetan populations, western Sichuan Province, China. Emerg Infect Dis 2005, 11:1866-1873

25. De U: Primary abdominal hydatid cyst presenting in emergency as appendicular mass: a case report. World J Emerg Surg 2009, 4:13. 
26. Li W: Investigation of Echinococcus species and echinococcosis in Ningxia. Endem Dis Bull 1986, 1:131-135.

27. Li W, Zhang G, Lin Y, Hong L: The occurrence of Echinococcus multilocularis Leukart, 1863 the natural animal host in China and its morphological study. Acta Zoo Sin 1985, 31:365-370.

28. Hong L, Lin Y: Studies on the development and histopathology of alveolar cestode of Echinococcus multilocularis in human and animal hosts. Endemic Dis Bull 1987, 2:51-59.

29. Wang XT: Scientific Investigation in Liupan Mountains. Ningxia: Ningxia People's Press, Yinchuan; 1989.

30. Yang YR, Craig PS, Vuitton DA, Williams GM, Sun T, Liu TX, Boufana B, Giraudoux P, Teng J, Li Y, et al: Serological prevalence of echinococcosis and risk factors for infection among children in rural communities of southern Ningxia, China. Trop Med Int Health 2008, 13:1086-1094.

31. Wang Z, Wang $X$, Liu X: Echinococcosis in China, a review of the epidemiology of Echinococcus spp. EcoHealth 2008, 5:115-126.

32. Anonymous: Ningxia animal slaughter inspection. Government Issues of Livestock and Economic Animal Disease Control. 145 Shenli St., Yinchuan, Ningxia 750001, P.R. of China: Ningxia People's Press; 2008:78-90.

33. Eckert J, Deplazes P: Biological, epidemiological, and clinical aspects of echinococcosis, a zoonosis of increasing concern. Clin Microbiol Rev 2004 17:107-135.

34. Xiao N, Qiu J, Nakao M, Nakaya K, Yamasaki H, Sako Y, Mamuti W, Schantz PM, Craig PS, Ito A: Short report: Identification of Echinococcus species from a yak in the Qinghai-Tibet plateau region of China. AmJTrop Med Hyg 2003, 69:445-446.

35. Wang $\mathrm{HL}$, Yin $Y C$, Ma C, Zhang $C Y$, Zhang XP, Cheng RP, Jing RF, Li M: Preliminary investigation of liver alveolar echinococcosis and liver cystic, echinococcosis in Xiji County, Ningxia. Zhongguo Ji Sheng Chong Xue Yu Ji Sheng Chong Bing Za Zhi 1991, 9:143-145.

36. Mu Y, Sueng Z: Alveolar hydatid disease of liver: clinical analysis of 113 cases. Endemic Dis Bull 1991, 6:64-68.

37. Budke CM, Jiamin Q, Zinsstag J, Qian W, Torgerson PR: Use of disability adjusted life years in the estimation of the disease burden of echinococcosis for a high endemic region of the Tibetan plateau. AmJTrop Med Hyg 2004, 71:56-64.

38. Scott PC, Godard V, Benabderrahmane C: Modeling risk areas for Echinococcus multilocularis egg survival in an urban park in France. Curitiba, PR, Brasil: Anais XV Simposio Brasileiro de Sensoriamento Remoto - SBSR; 2011:5989-5996. 30 De abril a 05 de maio de 2011, INPE.

39. Yang YR, Gray DJ, Ellis MK, Yang SK, Craig PS, McManus DP: Human cases of simultaneous echinococcosis and tuberculosis - significance and extent in China. Parasit Vectors 2009, 2:53.

40. Yang YR, Craig PS, Ito A, Vuitton DA, Giraudoux P, Sun T, Williams GM, Huang Z, Li Z, Wang Y, et al: A correlative study of ultrasound with serology in an area in China co-endemic for human alveolar and cystic echinococcosis. Trop Med Int Health 2007, 12:637-646.

41. Graham AJ, Danson FM, Giraudoux P, Craig PS: Ecological epidemiology: landscape metrics and human alveolar echinococcosis. Acta Trop 2004, 91:267-278.

42. Li L, Yan L, Feng Y, Qiao F: Study on risk factors of echinococcosis control in Ningxia. Ningxia Med J 2010, 30:24-27.

43. Anonymous: A veterinary system record. Ningxia Vet Bull 2010, 10:100-106.

doi:10.1186/1756-3305-5-146

Cite this article as: Yang et al.: Impact of anthropogenic and natural environmental changes on Echinococcus transmission in Ningxia Hui Autonomous Region, the People's Republic of China. Parasites \& Vectors 2012 5:146.

\section{Submit your next manuscript to BioMed Central and take full advantage of:}

- Convenient online submission

- Thorough peer review

- No space constraints or color figure charges

- Immediate publication on acceptance

- Inclusion in PubMed, CAS, Scopus and Google Scholar

- Research which is freely available for redistribution

Submit your manuscript at www.biomedcentral.com/submit
Ciomed Central 